\title{
EXTRAÇÃO AUTOMÁTICA DE REDE DE DRENAGEM GERADA A PARTIR DE DADOS OBTIDOS POR PERFILAMENTO A LASER
}

\author{
Marvin de Almeida Correa ${ }^{(\mathrm{a})}$, Cristiane Nunes Francisco ${ }^{(\mathrm{b})}$, Leticia da Cunha Mose Ferreira ${ }^{(\mathrm{c})}$ \\ (a) Universidade Federal Fluminense, Email: marvincorrea.geo@gmail.com \\ (b) Universidade Federal Fluminense, Email: cristianenf@id.uff.br \\ (c) Universidade Federal Fluminense, Email: leticiacmf@id.uff.br
}

\section{Eixo: GEOTECNOLOGIAS E MODELAGEM ESPACIAL EM GEOGRAFIA FÍSICA}

\begin{abstract}
Resumo
O presente trabalho tem como objetivo avaliar a extração automática de drenagem gerada a partir de dados obtidos por perfilamento a laser, na Bacia Hidrográfica do Rio Jacaré, localizada no município de Niterói, RJ. Para tanto foram extraídas automaticamente redes de drenagem com limiares distintos a partir de MDTs gerado por perfilamento a laser e por curvas de nível provenientes do mapeamento 1:25.000 do IBGE. Os experimentos executados demonstraram que os dados obtidos por perfilamento a laser apresentaram melhores resultados na extração automática da drenagem, especialmente nas regiões planas, no que se refere ao nível de detalhe do traçado das linhas de drenagem. Verificou-se também que limiares menores de fluxo acumulado geram redes de drenagem mais densas, com canais mais extensos e com quantidade de pequenos canais de primeira ordem. Contudo, em alguns casos, os canais não atingem o topo das cabeceiras, como em redes delineadas por fotointérpretes a partir da interpretação visual.
\end{abstract}

Palavras chave: extração automática de drenagem, LIDAR, modelos digitais de terreno.

\section{Introdução}

A rede de drenagem é esculpida pela ação das águas sobre a superfície terrestre, sendo condicionada pelas características fisiográficas dominantes no terreno, entre elas as estruturais, litológicas e geomorfológicas. O mapeamento da drenagem é basicamente realizado por um fotointérprete a partir da interpretação de um modelo estereoscópico, que consiste na sobreposição de imagens capturadas em ângulos diferentes, possibilitando a percepção das três dimensões - altura, largura e profundidade (COUTINHO et al., 2007).

Com o avanço das Geotecnologias, a extração de drenagem passa a ser realizada também de forma automática a partir de algoritmos aplicados aos Modelos Digitais de Terreno (MDTs). Esses modelos correspondem à representação altimétrica em uma superfície digital contínua, podendo ser obtidos através da interpolação de curvas de nível e pontos cotados, ou gerados por sensores remotos, como radares interferométricos e LIDAR (LIght Detection And Ranging).

A tecnologia LIDAR consiste em um sistema de sensoriamento remoto ativo que utiliza varredura óptico-mecânica e um feixe de laser como ferramenta de detecção (WEHR; LOHR, 1999). Seu 
OS DESAFIOS DA GEOGRAFIA FÍSICA NA FRONTEIRA DO CONHECIMENTO Instituto de Geociências - Unicamp

Campinas - SP

28 de Junho à 02 de Julho de 2017

princípio é similar ao do sistema de RADAR (RAdio Detection And Ranging), mas difere-se deste ao utilizar pulsos de laser ao invés da energia emitida na região de micro-ondas para suas aplicações.

O sistema de varredura laser mede as coordenadas tridimensionais $(\mathrm{x}, \mathrm{y}, \mathrm{z})$ de objetos sobre a superfície terrestre, tendo como princípio básico a emissão de um pulso de laser em direção aos objetos, que, após ser refletido pela superfície, retorna ao sistema em forma de eco. Este princípio pressupõe o registro do tempo decorrido entre a emissão e a captação do retorno, permitindo a obtenção da distância entre o sensor e o objeto (GALVANIN, 1984). A maioria dos sistemas de varredura laser usados em mapeamentos topográficos emite luz no comprimento de onda do infravermelho próximo (1040 a $1060 \mathrm{~nm}$ ), entretanto há levantamentos a laser que utilizam o espectro de luz visível $(532 \mathrm{~nm})$, geralmente usados em mapeamentos batimétricos, devido à sua capacidade de penetração na água (JENSEN, 2009).

A nuvem de pontos georreferenciados obtida pela tecnologia LIDAR é constituída por valores referentes a superfície, contendo, assim, pontos dos diversos estratos dos alvos terrestres (vegetação, edificações, solo etc.). Para extração dos pontos correspondentes ao terreno, é necessária a aplicação de um algoritmo de "filtragem" ou "classificação" (LOHMANN et al., 2000; BRIESE; PFEIFER, 2001), responsável pela identificação dos pontos levantados, discriminando-os de acordo com sua posição altimétrica na superfície.

A separação dos pontos em valores de terreno e superfície permite a geração de dois tipos de modelos, o Modelo Digital de Terreno (MDT), que caracteriza os fenômenos incidentes na superfície nua do terreno, isto é, exclui-se feições artificiais, como edificações e construções, e também as feições naturais como a vegetação, e o Modelo Digital de Superfície (MDS), que engloba não somente a superfície do terreno, mas também as feições naturais e artificiais (WACK, R.; WIMMER, 2002).

A tecnologia de varredura a laser tem sido aplicada em trabalhos, como a geração de MDTs com precisa informação altimétrica, em mapeamentos topográficos e cartográficos, em levantamentos de linhas de transmissão, rodovias, florestas, ferrovias, monumentos históricos, sítios arqueológicos, entre outros (NASCIMENTO JÚNIOR, 2006). De acordo com Schimalesky (2007), o uso do laser scanner para fins de sensoriamento remoto é recorrente em muitos países a mais tempo do que no Brasil, aqui utilizada pela primeira vez para fins de mapeamento apenas em 2001.

Beirão (2011) ressalta que para levantamentos tridimensionais, é possível a utilização de diferentes métodos convencionais, empregados conforme a escala (relacionada ao tamanho do objeto a ser medido) e complexidade (número de medidas necessárias para a aquisição) demandadas, como o uso de estação total ou instrumentos de GNSS (Global Navigation Satellite System), que fornecem informações $\mathrm{x}, \mathrm{y}, \mathrm{z}$ com alta precisão, mas que demandam tempo e possuem um alto custo, além de 
OS DESAFIOS DA GEOGRAFIA FÍSICA NA FRONTEIRA DO CONHECIMENTO

Instituto de Geociências - Unicamp

Campinas - SP

28 de Junho à 02 de Julho de 2017

apresentarem limitações em determinadas condições, como em levantamentos realizados em áreas cobertas por vegetação densa, por exemplo.

A geração de MDTs com alta resolução espacial através da tecnologia LIDAR, decorrente da capacidade de obter elevado número de pontos do terreno com informações tridimensionais, pode possibilitar a extração da rede de drenagem de modo refinado. Estudos realizados por Santos \& Francisco (2011), utilizando os modelos SRTM (90 m), TOPODATA (30 m), ASTER (30 m) e Projeto RJ-25 (20 m), demonstraram que a densidade da drenagem extraída automaticamente aumenta de acordo com a resolução espacial dos modelos, considerando o mesmo valor do fluxo acumulado e, ainda, que o traçado dos canais tende a retilineidade em modelos de menor resolução espacial mesmo quando estabelecido um limiar de fluxo maior.

Destaca-se também o fato de que em regiões de relevo plano, onde há presença de canais meândricos, são criados canais retilinizados, conforme registrado em trabalhos desenvolvidos por Santos \& Francisco (2011), Pereira \& Francisco (2013) e Andrades Filho et al (2009). A reduzida amplitude altimétrica nas áreas planas, quando representadas em MDTs de menor resolução espacial, impossibilita identificar a direção de fluxo, uma das etapas para a extração automática de drenagem, fazendo com que sejam construídos canais retilíneos. Além da forma, a extração automática de drenagem nas áreas planas tende a gerar maior densidade de canais do que se apresenta no terreno.

No entanto, é importante ressaltar que os próprios fotointérpretes, com bastante experiência técnica, relatam dificuldades em traçar a drenagem nesse tipo de terreno através da restituição convencional. Atualmente, nos bancos de dados digitais, é sugerido o atributo "geometria aproximada" às feições localizadas em terrenos planos (DSG, 2011). Nestas áreas, os canais são delineados quando o fotointérprete visualiza os cursos d'água ou os interpreta utilizando elementos de reconhecimento (cor, tonalidade, textura etc.) presentes na imagem, enquanto que, nas áreas de relevo acidentado, os canais são traçados, principalmente, utilizando como parâmetro a forma da encosta. O MDT com maior resolução espacial pode, portanto, aumentar a possibilidade de traçar os cursos d'água corretamente em terreno plano por representar menores desníveis altimétricos.

Considerando, assim, que a forma e a densidade dos canais obtidos pela extração automática da drenagem são dependentes da resolução espacial do MDT, este estudo tem como objetivo analisar as redes de drenagem obtidas por extração automática feita com base em MDTs gerado por dados de perfilamento de laser, que possibitam a geração de modelos com maior resolução espacial quando comparados a dados altimétricos obtidos por técnicas tradicionais de sensoriamento remoto.

A área de estudo é a bacia hidrográfica do Rio Jacaré, com cerca de $6 \mathrm{~km}^{2}$, pertencente à Macrobacia da Região Oceânica do município de Niterói (RJ), e que representa a maior bacia contribuinte ao sistema lagunar Piratininga-Itaipu. A bacia faz parte da Unidade Geomorfológica Maciços da Região 
OS DESAFIOS DA GEOGRAFIA FÍSICA NA FRONTEIRA DO CONHECIMENTO Instituto de Geociências - Unicamp

Campinas - SP

28 de Junho à 02 de Julho de 2017

dos Lagos que tem como características marcantes o alinhamento serrano isolado, morros de perfis arredondados ("Pães-de-Açúcar"), além de afloramentos rochosos cobertos por uma fina camada de detritos onde cresce a vegetação (VALERIANO, 2012). O alinhamento serrano atua como zona dispersora de águas entre o relevo colinoso e as baixadas confinadas dos sistemas lagunares, formadas por sedimentos fluvio-marinhos do quaternário.

A Bacia Hidrográfica do Rio Jacaré apresenta forma alongada, com relevo muito acidentado e reduzida área de relevo suave, correspondendo ao terraço fluvial e a planície costeira, densamente ocupada com uso urbano. A altitude mínima observada na bacia é de $0,1 \mathrm{~m}$, na foz do canal principal, e a máxima 407,3 m, correspondente à Pedra do Cantagalo, sendo a altitude média de $111,5 \mathrm{~m}$ (FRANCISCO et al., 2016).

\section{Materiais e Métodos}

Para realização do presente trabalho foram utilizados os dados provenientes do perfilamento a laser realizado no ano de 2014 recobrindo o município de Niterói, elaborado pela empresa TOPOCART, disponibilizado publicamente no site da Secretaria de Urbanismo e Mobilidade do Município de Niterói. Também foram utilizados os arquivos vetoriais de curvas de nível e hidrografia do mapeamento sistemático escala de 1:25.000 do Instituto Brasileiro de Geografia e Estatística (IBGE) do projeto RJ-25/IBGE.

Os dados de perfilamento a laser foram obtidos com densidade de 5 pontos $/ \mathrm{m}^{2}$, utilizando o sistema a laser aerotransportado modelo ALS-60. Este sensor trabalha com comprimentos de onda do feixe $1.064 \mathrm{~nm}$, opera com uma frequência de captação de pontos de $200 \mathrm{kHz}$ e possui amplitude operacional de 200 metros a 5.000 metros, com abertura máxima do ângulo de visada do laser de $75^{\circ}$ (TOPOCART, 2014). Como produtos do perfilamento estão disponíveis um arquivo de pontos, tendo a cota altimétrica como atributo, o que possibilita a geração de MDT, e um segundo arquivo, tendo como atributo a cota altimétrica somada à altura dos alvos terrestres, ou seja, a elevação do terreno, do qual pode ser gerado o MDS.

A obtenção desses dois produtos é possível devido a característica do sistema ALS-60 de realizar o registro de múltiplos retornos, possibilitando determinar a altura de objetos que estejam sobre a superfície mapeada, gerando uma nuvem de pontos seguindo o padrão do escaneamento (Figura 1) (TOPOCART, 2014). De acordo ainda com a empresa responsável pelo levantamento e processamento dos dados, o número e a distribuição dos pontos de apoio básico da aerotriangulação garantem precisões esperadas para a elaboração dos produtos cartográficos na escala de 1:1.000. Para o presente trabalho foi utilizado somente o arquivo de pontos contendo a cota altimétrica como atributo, objetivando a geração do MDT. 


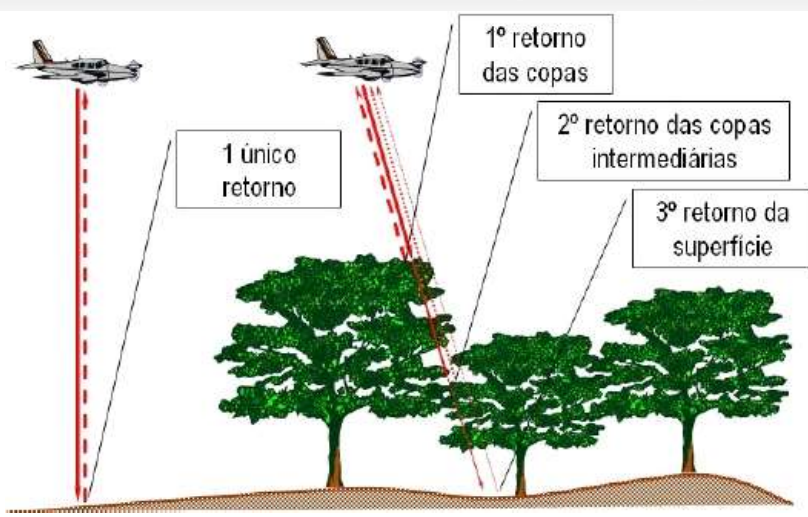

Figura 1 - Esquema de registro de retornos múltiplos utilizados no perfilamento a laser do Município de Niterói (Fonte: TOPOCART, 2014).

Os dados do projeto RJ-25/IBGE são parte da Base Cartográfica Vetorial Contínua do Estado do Rio de Janeiro, na escala 1:25.000, elaborada a partir de uma parceria entre o IBGE e o Governo do Estado do Rio de Janeiro, através da Secretaria de Estado do Ambiente (SEA-RJ). A base foi gerada a partir da restituição e interpretação visual de fotografias aéreas obtidas entre os anos de 2005 e 2006, na escala aproximada de 1:30.000, e por levantamentos em campo e informações de órgãos setoriais (IBGE, 2017).

A metodologia do presente trabalho está dividida em três etapas: (1) geração dos MDTs, (2) extração automática da drenagem e (3) comparação entre os resultados da extração automática da drenagem e a base de hidrografia do projeto RJ-25/IBGE.

Foram gerados dois MDTs a partir da ferramenta Topo to Raster disponível no sistema ArcGIS 10.0.4.4®, que consiste em um algoritmo de interpolação especificamente desenvolvido para geração de modelos hidrologicamente consistentes (ESRI, 2016).

O primeiro MDT foi gerado a partir dos valores altimétricos obtidos pelo perfilamento a laser, com resolução espacial de $1 \mathrm{~m}$. O segundo MDT foi gerado a partir do arquivo vetorial de curvas de nível com equidistância de 10 metros, oriundo do projeto RJ-25/IBGE. Esse último modelo também foi gerado com resolução espacial de $1 \mathrm{~m}$, visando a adequação das resoluções espaciais, a fim de permitir a comparação entre as redes de drenagem geradas por extração automática da drenagem com base nos dois modelos.

Após a geração dos MDTs foi realizada a extração automática da drenagem aplicando os algoritmos contidos na extensão ArcHydro do software ArcGIS 10.0.4.4®. A extração automática da rede de drenagem seguiu o método convencional cujos procedimentos estão descritos a seguir (MENDES; CIRILO, 2001).

1. Eliminação das depressões do MDT - substituição dos valores altimétricos espúrios pelos valores dos pixels vizinhos criando uma superfície de escoamento. 


\section{OS DESAFIOS DA GEOGRAFIA FÍSICA NA FRONTEIRA DO CONHECIMENTO Instituto de Geociências - Unicamp \\ Campinas - SP \\ 28 de Junho à 02 de Julho de 2017}

2. Geração da direção do fluxo - geração de uma grade que contém valores que indicam a direção do fluxo, definidos pelos valores entre 1 (L) e 128 (NE), identificada pela distribuição espacial dos valores altimétricos dos MDTs (Figura 2).

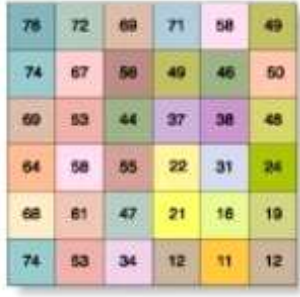

(1)

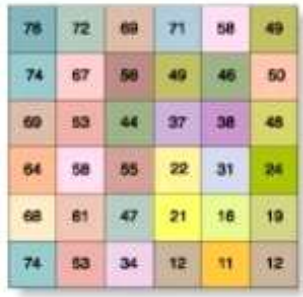

(1)

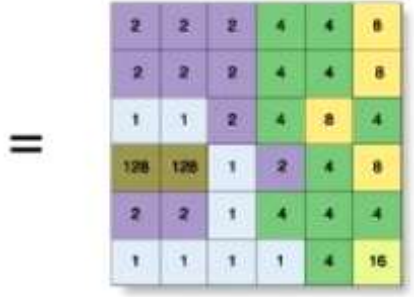

(2)

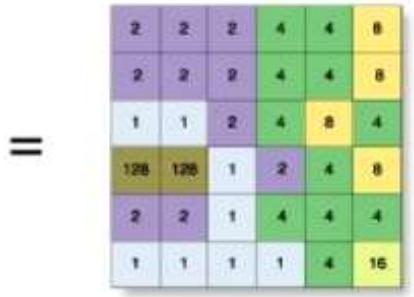

(2)

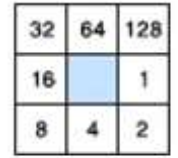

(3)

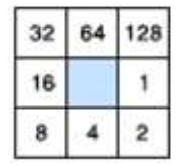

(3)

Figura 2 - MDT (1), grade de fluxo (2) e valores que indicam direção de fluxo (3) (Fonte: ESRI, 2017).

3. Geração do fluxo acumulado - geração de uma grade, a partir da direção do fluxo, contendo valores que indicam a acumulação do fluxo, ou seja, número de pixels direcionados para cada pixel da grade (Figura 3).

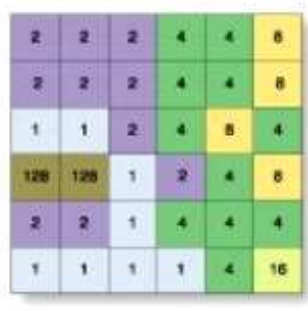

(1)

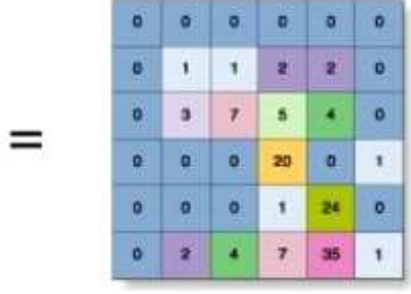

(2)

Figura 3 - Direção de fluxo (1) e fluxo acumulado (2) (Fonte: ESRI, 2017).

4. Especificação do valor do fluxo acumulado - seleção dos pixels na grade de fluxo acumulado que contenham valores de fluxo maiores que o valor especificado pelo usuário, gerando uma nova grade com pixels que demarcam os canais drenagem. Quanto menor o valor definido, maior a densidade de canais, pois é selecionada maior quantidade de pixels para o delineamento da drenagem.

Por fim, para análise das redes de drenagem geradas por extração automática, os resultados, derivados dos dois modelos e de diferentes valores de fluxo acumulado, foram comparados por meio de análise visual e análise morfométrica ao mapeamento da base de hidrografia do projeto RJ-25/IBGE. Foram 
utilizados como indicadores morfométricos a extensão total dos canais e a densidade de drenagem, esta definida por Horton (1945) como o comprimento médio de rios de uma bacia hidrográfica por unidade de área, expressa pela equação: $\mathrm{Dd}=\mathrm{L} / \mathrm{A}$, onde, Dd é a densidade de drenagem; L, o somatório do comprimento dos canais; e A, a área da bacia. 


\section{Resultados e Discussão}

A análise morfométrica dos dados, em conjunto com a análise visual, demonstra que a densidade da rede de drenagem está diretamente relacionada ao valor do limiar de fluxo acumulado. Nas redes geradas com menores de limiares, há maior quantidade de canais de primeira ordem, bem como o aumento da extensão dos canais na direção de suas cabeceiras. No sentido inverso, o uso de limiares maiores reduz a quantidade de canais de $1^{\text {a }}$ ordem, bem como a sua extensão, resultando no "recuo" dos canais nas suas cabeceiras. A Figura 4 apresenta três redes de drenagem extraídas do MDT gerado com dados do perfilamento de laser (LIDAR) e limiares de fluxo variando entre 2.000 e 60.000 .

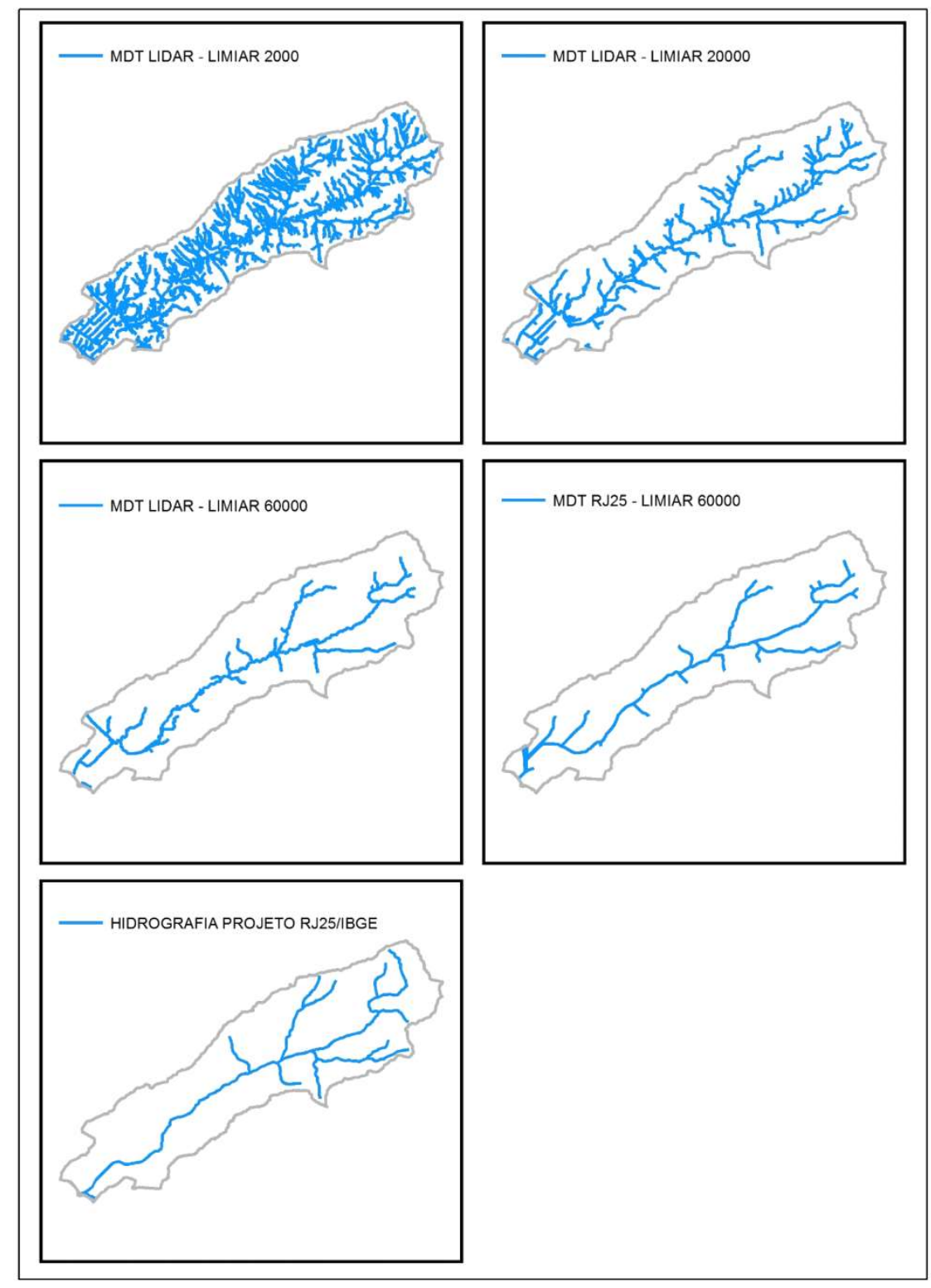

Figura 4 - Redes de drenagem geradas por extração automática de drenagem a partir dados de perfilamento a laser e curva de nível 1/25.000, e rede de drenagem restituída - Bacia do Rio Jacaré, Niterói, RJ. 
OS DESAFIOS DA GEOGRAFIA FÍSICA NA FRONTEIRA DO CONHECIMENTO Instituto de Geociências - Unicamp

Campinas - SP

28 de Junho à 02 de Julho de 2017

Para o limiar de fluxo acumulado igual a 60.000, a extensão total dos canais obtida foi de $18,13 \mathrm{~km}$ e a densidade de drenagem de $3,02 \mathrm{~km} / \mathrm{km}^{2}$ (Tabela I). O limiar 20.000 resultou em uma rede com 35,32 $\mathrm{km}$ de extensão total de canais e $5,88 \mathrm{~km} / \mathrm{km}^{2}$ de densidade de drenagem, representando aumento de 94\% dos valores de ambos indicadores em relação à rede do limiar anterior. Enquanto que, para o limiar 2.000, os valores são $16,96 \mathrm{~km}^{2}$ e $101,76 \mathrm{~km} / \mathrm{km}^{2}$, respectivamente, correspondendo a aumento de $461 \%$ em relação aos valores obtidos à rede do primeiro limiar apresentado, com um número excessivo de canais, inclusive delineados nos eixos de rua da área urbana.

Tabela I - Indicadores morfométricos das redes de drenagem extraídas automaticamente e da rede de drenagem restituída - Bacia do Rio Jacaré, Niterói, RJ.

\begin{tabular}{c|c|c|c}
\hline $\begin{array}{c}\text { Fonte da rede de } \\
\text { drenagem }\end{array}$ & $\begin{array}{c}\text { Limiar de fluxo } \\
\text { acumulado }\end{array}$ & $\begin{array}{c}\text { Extensão total dos } \\
\text { canais } \mathbf{( k m )}\end{array}$ & $\begin{array}{c}\text { Densidade de } \\
\left.\text { drenagem } \mathbf{( k m} / \mathbf{k m}^{\mathbf{2}}\right)\end{array}$ \\
\hline \multirow{2}{*}{ MDT LIDAR } & 2000 & 101,76 & 16,96 \\
\cline { 2 - 4 } & 20000 & 35,32 & 5,88 \\
\cline { 2 - 4 } & 60000 & 18,13 & 3,02 \\
\hline MDT RJ-25/IBGE & 60000 & 13,96 & 2,32 \\
\hline $\begin{array}{c}\text { Base de Hidrografia do } \\
\text { projeto RJ-25/IBGE }\end{array}$ & ----------------- & 12,94 & 2,15 \\
\hline
\end{tabular}

A partir dos testes com valores de limiares de fluxo acumulado, verificou-se que as redes de drenagem extraídas automaticamente, que obtiveram densidade de drenagem próxima à base de hidrografia restituída no projeto RJ-25/IBGE, foram geradas com valor de fluxo acumulado de 60.000 nos dois MDTs elaborados, ou seja, modelo derivado dos dados do perfilamento a laser e modelo gerado com base nas curvas de nível do projeto RJ-25/IBGE (Figura 4).

A rede extraída deste último modelo apresenta valores próximos, extensão total dos canais de 13,96 $\mathrm{km}$ e densidade de drenagem de $2,32 \mathrm{~km} / \mathrm{km}^{2}$, aos observados na base de hidrografia do projeto RJ25/IBGE, correspondendo, respectivamente, a $12,94 \mathrm{~km}$ e $2,15 \mathrm{~km} / \mathrm{km}^{2}$ representando uma diferença de $8 \%$ entre as duas redes aqui comparadas. Enquanto que o MDT gerado a partir do LIDAR apresenta valores maiores, com extensão total dos canais $18,13 \mathrm{~km}$ e $3,02 \mathrm{~km} / \mathrm{km}^{2}$, representando uma diferença de $40 \%$ em relação à base de hidrografia do projeto RJ-25/IBGE (Tabela I).

A análise visual, no entanto, demonstra que as duas redes de drenagem geradas com o valor de fluxo acumulado 60.000 apresentam resultados próximos, com a variação residindo na sinuosidade dos canais, expressa pelo maior número de vértices contido nas linhas de drenagem na rede gerada a partir dos dados do LIDAR comparada com a gerada a partir das curvas de nível do projeto RJ-25/IBGE (Figura 5). 

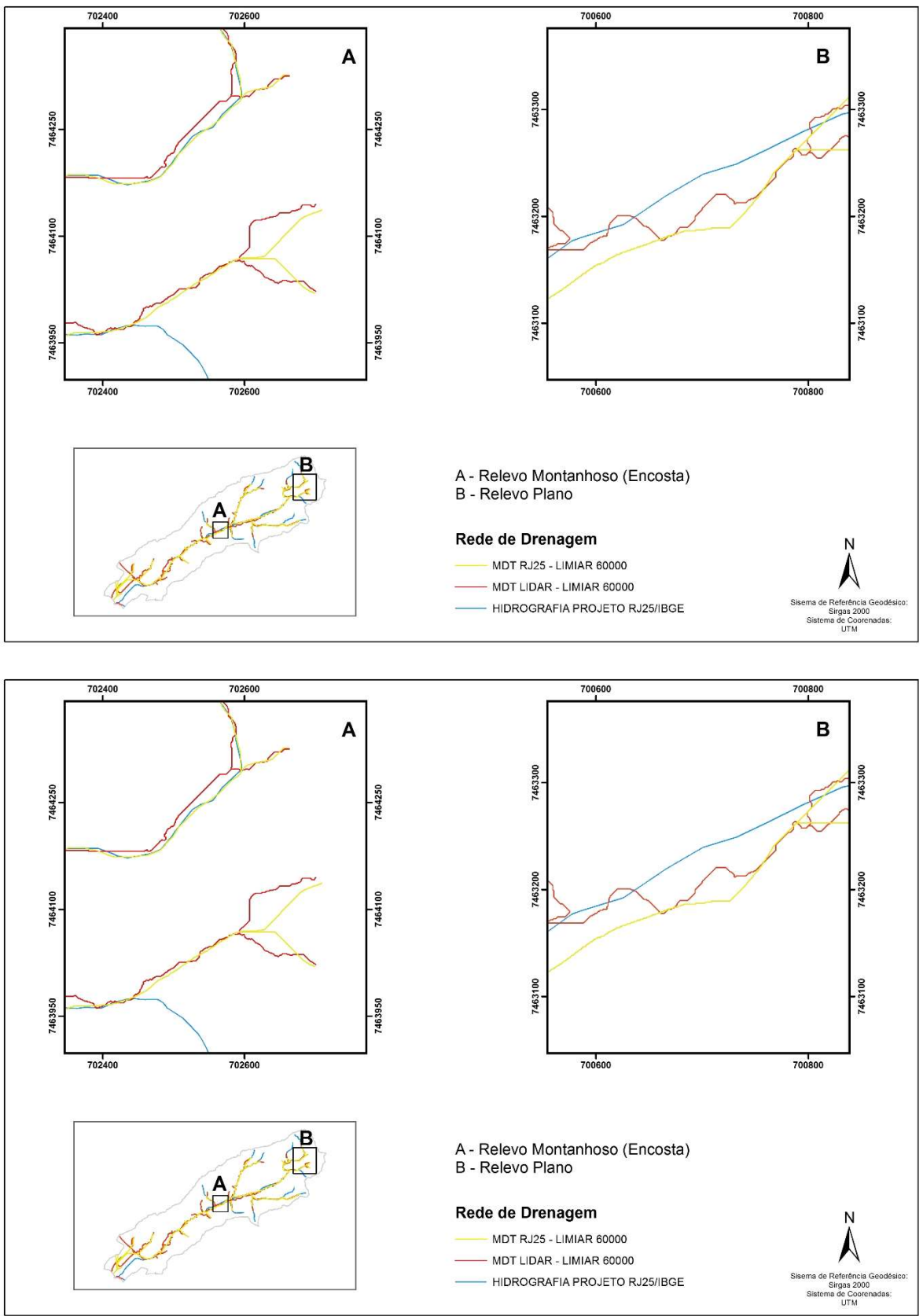

Figura 5 - Comparação entre as redes de drenagem situadas nas áreas de encosta (A) e área plana (B).

Este resultado pode ser explicado pela menor quantidade de informações altimétricas das curvas de nível com equidistância de $10 \mathrm{~m}$ na escala 1:25.000, gerando rede de drenagem com feições menos detalhadas. A retilineidade dos canais é, principalmente, identificada nas áreas planas, onde o desnível do terreno é menor do que a equidistância das curvas de nível, fazendo com que os canais sejam gerados de forma retilínea e, assim, os meandros não estejam representados (Figura 5B).

Cabe ressaltar, também, que as redes de drenagem extraídas automaticamente apresentaram resultados insatisfatórios quanto ao delineamento dos canais próximos a foz do rio principal, traçando canais inexistentes, em geral no traçado das vias públicas, e distantes do canal real. Além do pequeno 
OS DESAFIOS DA GEOGRAFIA FÍSICA NA FRONTEIRA DO CONHECIMENTO

Instituto de Geociências - Unicamp

Campinas - SP

28 de Junho à 02 de Julho de 2017

desnível altimétrico, esta área é densamente urbanizada com canais de drenagem alterados, inclusive, em parte, encontram-se tamponados.

Nas encostas, as redes geradas automaticamente seguem o eixo de concavidade, sendo que os canais resultantes do LIDAR mostraram-se mais sinuosos, independentemente do valor de fluxo acumulado.

Por fim, quando comparadas à base hidrográfica 1:25.000, restituída convencionalmente, com a diminuição do valor de fluxo acumulado, há aumento demasiado no número de pequenos canais de primeira ordem que, em geral, não correspondem a rede de drenagem do terreno e, ao mesmo tempo, o aumento da extensão de canais de drenagem de primeira ordem em direção às cabeceiras. Contudo, em geral, os canais não atingem o topo da cabeceira, conforme delineado pelo fotointérprete. Desta forma, para estender os canais, através da extração automática, é necessário diminuir o valor de fluxo acumulado, ao custo da proliferação de pequenos canais de primeira ordem.

\section{Conclusões}

Os resultados mostraram que a densidade de drenagem aumenta com a diminuição do limiar de fluxo acumulado devido ao maior número de canais gerados e o aumento de extensão dos canais de primeira ordem em direção às cabeceiras.

Para um mesmo limiar de fluxo acumulado e mesma resolução espacial do modelo, o MDT gerado a partir dos dados do LIDAR, quando comparado ao MDT gerado a partir das curvas de nível, gera rede de drenagem mais densa devido à maior extensão e quantidade de canais, bem como canais sinuosos, decorrente da maior disponibilidade de dados altimétricos do terreno.

A rede de drenagem obtida pelo LIDAR apresentou melhores resultados na extração automática da drenagem, principalmente nas regiões planas, no que se refere ao nível de detalhe do traçado das linhas de drenagem. No entanto, devido ao detalhamento do terreno obtido por meio de perfilamento a laser, nota-se a confusão do algoritmo em discriminar valores altimétricos representativos de depressões de canais de drenagem e depressões oriundas de outras alterações no terreno como estradas rebaixadas, valas abertas por ação antrópica e paleocanais, levando a criação de canais inexistentes ou com cursos irregulares nas áreas planas.

Considerando que a adoção de limiares de fluxo acumulado menos elevados aumenta a quantidade e a extensão dos canais em direção as cabeceiras, seria fundamental que os algoritmos de extração automática de drenagem incorporassem a opção de configuração de uma extensão mínima para criação de canais, impedindo que, com a diminuição do valor de fluxo, canais menores do que determinada extensão fossem criados e, ao mesmo tempo, fosse possível a aumento da extensão dos canais maiores, do que a extensão configurada, em direção às cabeceiras. 


\section{OS DESAFIOS DA GEOGRAFIA FÍSICA NA FRONTEIRA DO CONHECIMENTO \\ Instituto de Geociências - Unicamp \\ Campinas - SP \\ 28 de Junho à 02 de Julho de 2017}

Conclui-se, portanto, que os experimentos realizados neste trabalho apontam para o potencial do uso de dados obtidos por meio de perfilamento a laser no processo de extração automática da drenagem, no entanto faz-se necessário o aprimoramento dos algoritmos.

\section{Bibliografia}

ANDRADES FILHO, C.O.A.; ZANI, H.; GRADELLA, F.S. Compatibilidade da rede de drenagem obtida através de dados SRTM, ASTER e carta topográfica DSG: estudo de caso no Pantanal de Aquidauana. In: Anais $2^{\circ}$ Simpósio de Geotecnologias no Pantanal, Corumbá, 7-11 novembro 2009, Embrapa Informática Agropecuária/INPE, p.51-61.

BEIRÃO, C.C.B. O potencial do laser scanner terrestre para o Inventário do patrimônio arquitetônico. Dissertação de Mestrado. UFSC - Universidade Federal de Santa Catarina. Programa de Pós-graduação em Engenharia Civil. Florianópolis, 2011.

BRIESE, C.; PFEIFER, N. Airborne Laser Scanning and Derivation of Digital Terrain Models. In Grün/Kahmen (Eds.): Optical 3-D Measurement Techniques. Institut für Photogrammetrie und Fernerkundung I.P.F. Vienna. 2001

COUTINHO, H.J.S.; PETRY, A.; CARDOSO, F.C. Avaliação da utilização de técnicas de estereoscopia para apresentação de conceitos de geometria descritiva. Graphica Curitiba, Paraná, Brasil 2007.

DSG. Especificação Técnica para a Aquisição de Dados Geoespaciais Vetoriais. Diretoria de Serviço Geográfico do Exército Brasileiro, 2a Edição, 2011.

ESRI, Enviromental Systems Research Institute. ArcGIS Pro tool reference. Disponível em: $<$ http://pro.arcgis.com/en/pro-app/tool-reference/main/arcgis-pro-tool-reference.htm $>$. Acesso em: fevereiro de 2017.

FRANCISCO, C.N.; ROSAS, R.O.; CORREA, M.A; FARIAS, O.G. Diagnóstico Socioambiental e Socioeconômico: Caracterização Fisiográfica da Bacia Hidrográfica do Jacaré. Niterói: Universidade Federal Fluminense, 2016.

GALVANIN, E.A.S; POZ, A.P.D. Sistema de Varredura a Laser: Características, Processamento e Metodos de Interpolacão de dados. In: Anais do CNMAC v.2. 1984.

HORTON, R. Erosional development of streams and their drainage basins: hydrophysical approach to quantitative morphology. Geological Society of America Bulletin, 1945, v.56, pp. 275-370. Disponível em: $<$ http://www.geos.ed.ac.uk/homes/s0451705/horton 1945.pdf $>$. Acesso em: fevereiro de 2017.

IBGE. Catálogo de Metadados Geográficos. Projeto RJ-25. 2017. Disponível em: <http://www.metadados.geo.ibge.gov.br/geonetwork ibge/srv/por/main.home>. Acesso em: fevereiro de 2017. 
JENSEN, J. R. Sensoriamento Remoto do Ambiente: uma perspectiva em recursos terrestres. São José dos Campos. 2009. 598 p.

LOHMANN, P.; KOCH, A.; SCHAEFFER, M. Approaches to the filtering of LASER scanner data. The International Archives of Photogrammetry and Remote Sensing, Amsterdam, 2000, v. 33 (B3).

MENDES, B.; CIRILO, A. Geoprocessamento em recursos hídricos: princípios, integração e aplicação. Porto Alegre: ABRH. 2001. 536p.

NASCIMENTO JÚNIOR, J. O., SCHULER, C. A. B., CAVALCANTE, R. B. S. Sistema Laser Scanner. In: Simpósio Regional de Geoprocessamento e Sensoriamento Remoto, 3., 2006, Aracaju. Anais eletrônicos. Universidade Federal de Pernambuco, 2006.

PEEL, M. C; FINLAYSON, B. L; MCMAHON, T. A. Updated world map of the Koppen-Geiger climate classification. Hydrology and Earth System Sciences Discussions, European Geosciences Union, 2007, 11 (5), pp.1633-1644.

PEREIRA, V.F.; FRANCISCO, C. N.. Mapeamento da rede de drenagem por extração automática: avaliação de algoritmos. In: Congresso Brasileiro de Geoprocessamento, 2013, Rio de Janeiro. Congresso Brasileiro de Geoprocessamento, 2013.

SANTOS, L.C.S.; FRANCISCO, C. N.. Avaliação dos Modelos Digitais de Elevação aplicados à extração automática de redes de drenagem. In: XV Simpósio Brasileiro de Sensoriamento Remoto, 2011, Curitiba. XV Simpósio Brasileiro de Sensoriamento Remoto. São Jose dos Campos: INPE, 2011.

SHIMALESKY, V. Avaliação da qualidade da informação altimétrica derivada da varredura a LASER em uma região coberta por vegetação: um estudo de caso. Dissertação de Mestrado pelo Programa de PósGraduação em Ciências Geodésicas - Universidade Federal do Paraná. Curitiba - Paraná, 2007.

TOPOCART. Relatório Técnico Final Levantamento Aerofotogramétrico e Perfilamento a Laser Niterói RJ. Brasília: Topocart. 2014.

VALERIANO, C. M. et al. Geologia e Recursos Minerais da Folha Baía de Guanabara SF.23-Z-B-IV, estado do Rio de Janeiro escala 1:100.000. Belo Horizonte: CPRM, 2012.

WEHR, A.; LOHR, U. Airborne laser scanning-an introduction and overview. ISPRS Journal of Photogrammetry \& Remote Sensing, v. 54, p. 68-82, 1999.

WACK, R.; WIMMER, A. Digital Terrain Models from Airborne LASER Scanner Data - A grid Approach. International Archives of Photogrammetry. Remote Sensing, 2002, v. 34 (B3), pp. 293-296. 